\title{
Diálogos com Rousseau e Emmi Pikler para Pensar a Educação da Criança de Zero a Três Anos
}

\author{
Ordália Alves de Almeida ${ }^{1}$ \\ Maria Eugênica Bordignon Nachif ${ }^{2}$ \\ Ana Paula Melim
}

\begin{abstract}
RESUMO
O trabalho docente com crianças pequenas no contexto atual, tem se tornado cada vez mais presente nos cursos de formação de professores. Este artigo aborda especialmente os pressupostos para a ação docente e objetiva desenvolver uma triangulação entre as contribuições teóricas que abordam a educação dessa faixa etária e a atividade docente numa instituição educativa. As discussões teóricas trazem contribuições e possibilidades para se dissertar e refletir sobre a prática docente em salas de Educação Infantil, para tanto, estabelecemos uma relação entre os autores Rousseau (1712 - 1778) e Pikler (1902 - 1985), que abordam em tempos distintos pressupostos teórico-práticos que contribuem para a formação de professores/as de crianças pequenas. Realizamos, inicialmente, estudos de fundamentação teórica, para em seguida, com a sustentação de um Protocolo de Observação, acompanharmos a prática de uma professora de crianças de zero a três anos. Estabelecemos a relação entre teoria e prática, as concepções dos pensadores estudados, referências para a educação da infância, evidenciando o que deve constituir a prática docente em sala de Educação Infanti e no processo educativo. Constamos que a ação docente entrelaça concepções teórico-práticas e se constituem em novas contribuições para a formação de professoras dentro das salas de crianças de zero a três anos de idade.
\end{abstract}

Palavras-Chave: Educação Infantil. Identidade Profissional. Prática Docente com Crianças de zero a três anos.

\section{ABSTRACT}

Teaching work with young children in the current context has become increasingly present in teacher training courses. This article deals especially with the assumptions for teaching

\footnotetext{
${ }^{1}$ Doutora em Educação; Professora titular aposentada da UFMS; Presidente da Câmara de Educação Superior do Conselho Estadual de Educação; Membro do Fórum Permanente de Educação Infantil de MS; Membro da Rede Nacional da Primeira Infância e Professora da Faculdade Insted - Campo Grande-MS.

${ }^{2}$ Graduada em Pedagogia pela Faculdade de Educação da UFMS. Professora de Educação Infantil do Ninho Jardim de Infância, Campo Grande-MS.

${ }^{3}$ Doutora em Educação; Coordenadora do Curso de Pedagogia da Unicversidade Católica Dom Bosco-UCDB; Professora do Curso de Pedagogia da UCDB; Coordenadora do Fórum Permanente de Educação Infantil de MS. Conselheira Titular do Conselho Municipal de Educação - CME.
} 
action and aims to develop a triangulation between the theoretical contributions that address the education of this age group and the teaching activity in an educational institution. Theoretical discussions bring contributions and possibilities to dissert and reflect on the teaching practice in Early Childhood Education classrooms, for that, we established a relationship between the authors Rousseau (1712 - 1778) and Pikler (1902 - 1985), who address in distinct times theoretical and practical assumptions that contribute to the training of teachers of young children. We conducted, initially, studies of theoretical foundation, and then, with the support of an Observation Protocol, we monitor the practice of a teacher of children from zero to three years old. We established the relationship between theory and practice, the conceptions of the studied thinkers, references for childhood education, showing what should be the teaching practice in the Infanti Education classroom and in the educational process. We note that the teaching action intertwines theoretical and practical concepts and constitutes new contributions to the training of teachers within the classrooms of children from zero to three years of age.

Keywords: Early childhood education. Professional Identity. Teaching Practice with Children from zero to three years old.

\section{Introdução}

O escrito que aqui se delineia busca construir uma perspectiva sobre a formação de professores para atuar com crianças com crianças de zero a três anos, envolvendo teoria e prática em salas de Educação Infantil. Nessa perspectiva, a formação de professores para atuar com crianças dessa faixa etária deve ter como referência criação de condições importantes às aprendizagens infantis.

Contemplamos neste artigo o que estudiosos, que são referência para a educação, trazem como aspectos principais para o desenvolvimento das crianças e o que se realiza em salas de instituições de Educação Infantil, traçando um percurso das contribuições dadas, especialmente, Jean Jacques Rousseau (1712 - 1778), a fim de enfatizar o respeito à natureza infantil e sua liberdade e Emmi Pikler (1902 - 1985), que aborda em sua teoria, temáticas como a autonomia, o movimento livre e o livre brincar na primeira infância. Ambos os estudiosos, apesar da distância temporal, trazem em suas concepções pontos considerados relevantes à formação de professores de crianças de zero a três anos.

A observação acurada de uma turma, em uma instituição pública de Educação Infantil, com crianças na faixa etária de 1 ano a 1 ano e meio de idade, nos permitiu realizar uma análise comparativa entre o que é proposto pelos teóricos abordados e o que o fazer docente revela, explicitando indicações teórico-práticas para a docência na Educação Infantil.

No primeiro momento realizamos um estudo acerca do que dizem os teóricos abordados, constatando a relevância do cuidado, da liberdade da criança e da sua autonomia na Educação Infantil. Em um segundo momento, trazemos explanações sobre as identidades das professoras de Educação Infantil, não apenas como profissionais, mas considerando a 
essência afetiva de quem trabalha com crianças pequenas. Em seguida discutimos sobre o que os documentos oficiais trazem como relevante, e como são assegurados os direitos das crianças pequenas. Constamos que a ação docente entrelaça concepções teórico-práticas e se constituem em novas contribuições para a formação de professoras dentro das salas de crianças de zero a três anos de idade.

\section{O Que Expressam Teorias Sobre a Educação das Crianças de Zero a Três Anos: Construções Históricas}

A realização de estudos sobre a educação infantil exige aprofundamentos teóricos que dêem sustentação a reflexões pertinentes à prática docente. Num primeiro momento, interessa-nos evidenciar as contribuições teóricas de dois grandes autores, o primeiro deles é Jean Jacques Rousseau (1712- 1778), autor que já no século XVIII apresentava o prenúncio de uma proposta educacional para as crianças de zero a três anos em sua obra O Emílio ou da Educação.

A segunda é Emmi Pickler (1902 - 1984), autora que no século XX realizou um trabalho educativo e, ao mesmo tempo, o teorizou para que mais profissionais pudessem ter acesso às suas contribuições e perspectivas para realização de uma educação que privilegiasse 0 desenvolvimento autônomo das crianças de zero a três anos.

\section{Rousseau e o Respeito à Natureza Infantil}

Voltar a Rousseau tem um sentido todo especial ao que nos propuzemos realizar, pode não ser hoje o ideal para a educação das crianças de zero a três anos, mas é o indicativo da gênese de uma proposta educativa. Sua obra carrega em si um valor inestimável, que não pode ser desprezado, quando queremos compreender a essência da educação nesses primeiros anos de vida.

Buscamos em Rousseau a compreensão de como se dá a relação social das crianças primeiramente em família, e expandindo-se ao mundo por intermédio da relação com a professora. Para tal, por meio do livro "Emilio ou Da Educação", encontramos uma idealização de uma criança pelo próprio autor, que ao introduzir suas percepções, busca evidenciar, em um primeiro momento, sobre o aprisionamento da criança recém-nascida, que tem seus próprios movimentos limitados por atas e vestimentas, por um cuidado excessivo com o seu corpo.

Para Rousseau (2017), deve-se dar a oportunidade para que a criança tenha desenvolvimento pleno de seu corpo logo que nasce, e dada essa importância, enfatizamos:

Colocai-a num grande berço bem estofado, no qual possa mover-se à vontade e sem perigo. Quando começar a se fortalecer, deixai-a rastejar pelo quarto; deixai que desenvolva e estenda seus pequenos membros; vê-los-ei reforçarem-se a cada dia. Comparai-a a uma criança bem enfaixada, da mesma idade, e surpreender-vos-ei com a diferença de seus respectivos progressos. (ROUSSEAU, 2017, p. 69) 
É interessante, ainda, ressaltar que a necessidade de libertar o corpo da criança desde cedo para que possa desenvolver sua autonomia é justificada também pelo próprio cuidado, para que esta aprenda, desde cedo, a se proteger do perigo eminente. Percebemos com frequência que pais, mães e professores costumam fazer justamente o contrário, procuram fazer pela criança o que ela poderia fazer sozinha, acreditando ser uma forma de protegê-la, porém, mal sabem essas pessoas que estão apenas limitando o aprendizado dessa criança.

O princípio fundamental da educação na primeira infância para Rousseau é o respeito do adulto ao mundo da criança.

Para não corrermos atrás de quimeras, não nos esqueçamos do que convém à nossa condição. A humanidade tem seu lugar na ordem das coisas, e a infância tem o seu na ordem da vida humana: é preciso considerar o homem no homem e a criança na criança. Determinar para cada qual o seu lugar e ali fixá-lo, ordenar as paixões humanas conforme a constituição do homem, é tudo o que podemos fazer pelo seu bem estar. (ROUSSEAU, 1995, p. 69).

A criança é um ser que está vivendo uma momento especial e deve receber a atenção e o respeito merecido por parte dos adultos.

No que diz respeito aos cuidados com a criança pequena, o autor ressalta ainda ser necessário ter atenção à higiene para com esta, apontando o banho como uma forma de auxiliar no desenvolvimento da resistência do corpo (ROUSSEAU, 2017, p. 68). O autor é sensível à causa e necessidade da criança pequena, busca defender que a criança começa a conhecer o mundo a partir do momento em que nasce, sendo este um aprendizado natural, que se antecipa diante dos outros aprendizados escolarizados. Também, uma criança recém-nascida tem a afetividade como norteadoras do primeiro aprendizado, sendo o prazer e a dor os maiores termômetros desse momento da vida. Uma das questões claramente retratadas são as necessidades da criança, desde a mais tenra idade.

A aprendizagem deve ser gradativa, para a vida, portanto, o cuidado com a vida deve se iniciar desde a primeira infância. $\mathrm{O}$ autor defende a autonomia da criança, ainda como um preparo, uma vez que orienta a necessidade de tocar e manusear tudo o que vê, para que possa explorar todas as sensações, tornando tudo à sua volta significativo e uma ferramenta de aprendizado. Aqui trazemos, então, o que busca referenciar como uma aprendizagem gradativa:

Começo mostrando a Emílio uma máscara de aspecto agradável. Em seguida, alguém coloca diante dele a mesma máscara sobre o próprio rosto; ponho me a rir, todo mundo ri e a criança ri assim como os outros. Pouco a pouco, eu a acostumo a máscaras menos agradáveis, e por fim, a figuras hediondas. Se conduzi bem minha gradação, longe de assustar- se com a última máscara, ela rirá dela assim como riu da primeira. Depois disso, não temo mais que se assuste com máscaras. (ROUSSEAU, 2017, p. 73) 
Chama atenção também ao cuidado para que a criança pequena não se torne dominadora daquele que a cuida, no contexto de Rousseau, a sua Ama. Uma vez que é percebido que, ao se manifestar em desejo ou necessidade de algo, e se tem em suas mãos assim que requisitado, a necessidade deixa de sê-lo e passa a ser um comando, tornando a criança um pequeno senhor. $\mathrm{O}$ autor critica essa prática e orienta que a criança seja ignorada para que perceba a necessidade de fazer por si só o que precisa, e em outra opção, que sua cuidadora leve a criança até o que quer alcançar, e não alcance, entregando diretamente o que ela quer.

Assim, constatamos que a obra de Rousseau é uma referência importante para quem atua com crianças na faixa etária de zero a três anos. Uma obra produzida no século XVIII apresenta aspectos importantes para uma educação que deve valorizar e respeitar as crianças desde pequenas.

\section{Emmi Pikler e o Desenvolvimento Autônomo das Crianças}

A respeito da concepção de desenvolvimento de Emmi Pikler, buscamos nos referenciar no livro "Educar os Três Primeiros Anos: a Experiência Lóczy (FALK, 2011)", que apresenta a história e os principais aspectos do cuidado e da autonomia para o desenvolvimento da criança pequena. É recente a abordagem de Pikler na literatura do campo da educação, seu nome, ou referências a Lóczy vem se traduzindo em expressivas contribuições para a educação das crianças pequenas e para a formação de professores.

O ponto de convergência entre Emmi Pikler e Rousseau está na discussão sobre a autonomia e liberdade do movimento da criança, partindo do pressuposto de que ambos, apesar de terem vivido em períodos históricos distintos tratam dos primeiros anos de vida da criança e relacionam-se quando ressaltam aspectos importantes para o desenvolvimento infantil. Os posicionamentos defendidos por Pikler resultam na prática do cuidado com crianças pequenas e dos conhecimentos da medicina, promoveu uma observação minuciosa a respeito do conforto, da liberdade, da autonomia e desenvolvimento da criança pequena.

Grande importância é dada à necessidade de que as crianças pequenas ou bebês tenham um adulto referência, tanto do ponto de vista social, quanto afetivo, educacional e moral, com responsabilidade e comprometimento com a realidade da criança. É necessário que a relação entre crianças e professora -adulto referência seja estável e afetiva, considerando as necessidades individuais, a forma de reagir às expressões para deixar as crianças confortáveis em diversas situações, desde o momento dos cuidados (a troca de fraldas, a forma de dar banho, vestir a roupa, sempre com carinho e sem pressa), até o desenvolvimento pleno de cada uma, promovendo sua autonomia, por meio do livre brincar e do movimento livre.

Essas crianças não devem permanecer ociosas, dentro de berços, mas em constante ação com aquilo que lhe dá prazer, devem ter sempre a possibilidade de brincarem, movimentarem-se, experimentarem sensações novas do cotidiano, a todo o momento, por iniciativa própria, com que lhes chamam a atenção e à professora cabe proporcionar organizar os tempos e espaços que respeitem as crianças. Percebemos também que dentro da estrutura 
educativa referenciada na aborgagem pikler, a participação das famílias tem grande importância, pois para que ocorra um desenvolvimento pleno das crianças, os pais devem valorizar a realidade individual de seus filhos, e da necessidade de estabelecer uma relação sempre afetiva nos momentos de cuidados e educação. Para Falk (2011), a atenção da família para com a criança deve vir acompanhada da palavra "qualidade".

É interessante compreender que a autonomia buscada para a criança tem o sentido de que essa se apropria melhor do que está aprendendo por iniciativa própria, o que também reforça a capacidade de confiança e de aprendizado do bebê e da criança pequena, ou seja:

[...] a atividade de movimento e de jogos livres - sem a participação iniciadora ou modificadora do adulto - reforça as possibilidades especiais de "aprendizagem" do bebê e da criança pequena que nenhuma outra coisa pode substituir (FALK, 2011, p. 35).

Com base nesta reflexão, levantamos aqui um questionamento a despeito das atitudes de muitas professoras para com crianças dessa idade: se a independência do bebê e da criança pequena é importante, e deve ser promovida, afim de oportunizá-las acesso aos conhecimentos, desenvolver a autoconfiança e explorar o mundo pelo seu próprio interesse, por que vemos em tantas instituições atividades puramente direcionadas pelas professoras, que limitam a possibilidade da descoberta pelo prazer de conhecer da criança? Um das atitudes não é recomendado, diríamos até mesmo pela própria Emmi Pikler, é a atividade com interferência do adulto, pois:

A intervenção do adulto, ensinando ou simplesmente interferindo nos movimentos e
nos jogos do bebê, não apenas perturba a situação de independência, substituindo o
interesse do bebê por seus próprios objetivos, como também aumenta artificialmente
a dependência da criança; enquanto que a atitude de respeito à autonomia coloca, em
lugar de um comportamento possessivo e autocrático dos pais, o fundamento de um
sistema de relações pais-filhos em que ambos se consideram e confiam mutuamente (FALK, 2011, p. 35-36).

Comumente, nas instituições de Educação Infantil, observamos que o trabalho para o desenvolvimento da criança é realizado com forte interferência das professoras, levando-as a agirem passivamente no cotidiano. Ressalta-se, entretanto que nem todos os teóricos da Educação Infantil enfatizam a autonomia como um dos pontos principais para o desenvolvimento da criança pequena.

No que diz respeito ao desenvolvimento da criança e ao seu próprio prazer e vontade, também somos concordantes com a abordagem Pikler, uma vez que o bem-estar da criança é de maior proporção quando ela faz aquilo que propõe. Para Falk (2011), a ciência nos ensina que todo ato desejado e executado ativamente pelo sujeito tem para este consequências imediatas e, a longo prazo, muito mais enriquecedoras que os atos impostos e suportados.

Outro aspecto importante em nossa reflexão, no que diz respeito a abordagem de Emmi 
Pikler, é a observação do ponto de vista das professoras e das crianças. Para quem entra na sala de Educação Infantil com o objetivo de colaborar para o desenvolvimento global da criança, todo e qualquer movimento e atividade deve ser objeto de análise para compreender o desenvolvimento dessa, enquanto que para a criança, o que ocorre a todo o momento é o ato de explorar todas as possibilidades a sua volta.

O ato de observar tem grande importância, pois é na observação diária das atividades da criança que se pode avaliar o desenvolvimento global desta, como a forma que se movimenta, o tempo que leva para aprender posições novas e resolver situações de conflito em que se encontra. É relevante também, pois a própria criança está sempre observando, e é dessa forma que busca descobrir o mundo e aprender, avalia o que vê, o que a chama atenção, experimenta as possibilidades que ali estabelece, e através do que vivencia, realiza novas descoberta.

Nesse contexto é configurada uma relação entre a autonomia da criança e a observação da professora, o adulto que observa o desenvolvimento infantil e respeita a liberdade de movimento da criança, não interrompendo-a em seu processo de descoberta, oportuniza maiores possibilidades de aprendizagem, descoberta e criação. Esse respeito enseja que o adulto crie as oportunidades e um ambiente apropriado para que a criança continue seu desenvolvimento.

Temos podido constatar com frequência que a observação e a valoração dessa atividade autônoma (motricidade livre, manipulação, investigação, iniciativas da criança nas suas relações com os adultos) induzem ao respeito no adulto que se encarrega de cuidar da criança: esse respeito se torna um componente importante de sua relação (FALK, 2011, p. 52).

Todos esses aspectos abordados por Emmi Pikler contribuem para o delineamento de propostas pedagógicas que respeitem a especificidade do atendimento às crianças de zero a três anos. Não podemos negligenciar com as crianças pequenas, pois elas estão em um momento da vida em que constroem estruturas mentais, cognitivas, sociais e afetivas que se constituem como base à sua formação humana.

\section{O Que se Apresenta na Prática Docente: Observando uma Realidade de Educação Infantil}

A realização de uma revisão teórica sobre aspectos importantes para uma prática educativa com crianças de zero a três anos desencadeia questionamentos sobre como, no contexto atual, dá-se o seu desenvolvimento com crianças dessa faixa etária. Vimos ser necessário realizar observações de uma prática docente, delimitando para as reflexões as vivências como ato que deve proporcionar às crianças seu desenvolvimento pleno.

Realizamos a observação em um Centro de Educação Infantil, na cidade de Campo Grande (MS), que oferece atendimento em período integral para as crianças, um espaço que 
possibilita a realização das mais diversas atividades, promovendo situações de experiências importantes às suas aprendizagens, estrutura adequada e recursos necessários a uma prática educativa de qualidade.

A observação foi realizada em uma turma com crianças de um ano a um ano e meio de idade, em período integral. Foram levados em conta aspectos teóricos abordados, principalmente no que diz respeito ao aprendizado autônomo, o respeito ao livre movimento e a relação de afetividade entre professoras e crianças. Para tanto, recorremos a um protocolo, que considerou aspectos relevantes ao desenvolvimento das crianças pequenas, concernetes ao espaço físico, rotina, organização da professora, relações sociais e dinâmica metodológica.

O ambiente educativo é organizado de forma a possibilitar que as crianças andem e movimentem-se livremente, tendo liberdade para agir, interagir, investigar e descobrir. Além de um tapete que ocupa uma parte da sala, há vários brinquedos para que as crianças possam manusear.

Figura 1. Berçário.

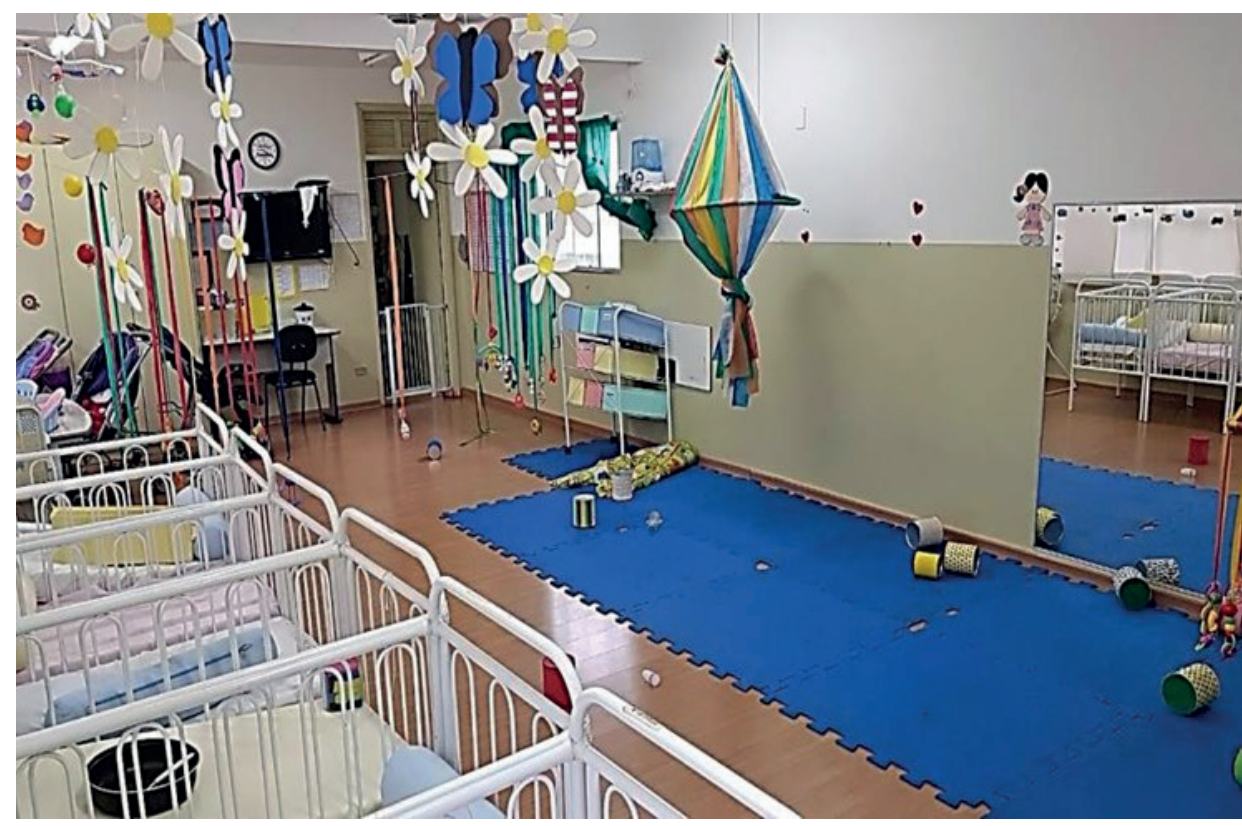

Fonte: acervo particular.

A dinâmica da sala desenvolve-se, a partir do plano de atividades realizado em conjunto com a coordenação. Quanto aos cuidados com os aspectos fisiológico dos bebês, os mesmos são esquematizados nos quadro afixados nas paredes da sala dos bebês, em que as professoras anotam ao longo do dia o comportamento das crianças, considerando a alimentação, a saúde e as relações estabelecidas com outras crianças.

O plano de atividade das professoras prevê que as crianças estejam em constante ação, tendo à sua disposição brinquedos estruturados ou não e objetos, que lhes permitem brincar e movimentarem-se livremente. Em sua maioria, as atividades desenvolvidas oportunizam 
que as crianças fiquem livres, em alguns momentos optam por participar das atividades propostas a partir do direcionamento da professora. Os brinquedos diversos são disponibilizados na sala, e por um tempo de aproximadamente 15 minutos, as crianças permanecem brincando e explorando as possibilidades de ação com cada brinquedo encontrado. Em alguns momentos, as atividades direcionadas chamavam mais atenção, como a dança, leitura e atividades motoras com objetos.

Aqui, buscamos enfatizar mais uma vez o que a perspectiva de Emmi Pikler apresenta grande contribuição para se promover o desenvolvimento infantil no movimento cotidiano e na interação das crianças oportuniza-se a aprendizagem autônoma, o livre brincar e o movimento livre. Ressaltamos que a criança livre para agir tem maiores possibilidades de aprendizado, ou seja:

A criança pequena também pode modificar seu projeto de ação e recomeçar suas tentativas mais tarde. Por exemplo, quer recuperar a cesta que the caiu fora da grade do cerrado. Não pode, não encontra o gesto adequado, a cesta não passa. A criança está só, não espera a ajuda do adulto. Tenta conseguir a cesta de tempos em tempos, impacienta-se. [...] Passa algum tempo contemplando e depois tenta recuperar a cesta. [...] A aceitação do fracasso momentâneo e a modificação flexível dos planos de ação também fazem parte da aprendizagem (FALK, p. 47, 2011).

A professora tem papel importante nesse processo de promoção da iniciativa infantil, levando as crianças a agirem autonomamente. É no cotidiano que as crianças podem ter acesso a situações de experiências que promovam a ação autônoma.

A rotina da turma evidencia que as professoras sempre buscam trabalhar os aspectos de desenvolvimento das crianças. Os horários de lanche, almoço e jantar são sempre no mesmo momento do dia, e os bebês já estão acostumados com a rotina. $O$ horário do banho é monitorado, porém, as professoras não tem pressa para dar banho em cada bebê, tentando deixá-los confortáveis com a atividade. As trocas de fralda são feitas no momento em que as crianças necessitam, porém, notamos que as professoras tem mais atenção a isso após o horário das refeições, e próximo ao horário dos banhos.

As refeições são dadas às crianças pelas professoras, sendo que, cada uma delas alimenta três ou quatro crianças ao mesmo tempo. Os bebês geralmente são posicionados em cadeirões, carrinhos de bebê, no colo, ou no chão, de frente para a professora.

O momento do sono acontece entre $11 \mathrm{~h}$ e $13 \mathrm{~h}$, após o banho. As professoras posicionam os colchões em cima do tapete da sala, e à medida que sentem sono, algumas se deitam sozinhas e dormem, e outras são colocadas nos carrinhos de bebê, no bebê-conforto ou no berço, e são ninadas para dormir. Todas as crianças são respeitadas nesse momento, sendo que nenhuma professora as força a dormir ou acordar. Todas dormem e acordam no momento em que tem necessidade. Nos momentos da alimentação, os bebês também são considerados de forma individual de acordo com suas necessidades, uma vez que à medida que rejeitam a comida, as professoras não insistem mais de duas vezes, deixando-as a von- 
tade para comerem apenas a quantidade que as satisfaçam.

Todos os dias os bebês são levados para a área externa (figura 2) do berçário para brincarem livremente. Nesse local há vários brinquedos, e os bebês estão em constante movimento e as professoras observam atentamente para o caso de alguma criança colocar-se em risco. Os bebês também são levados ao parque de areia todos os dias, deixando de ir apenas quando a areia está molhada ou muito fria. No parque também brincam livremente, porém, as professoras estão atentas às crianças, observando seus movimentos e suas conquistas. Notamos também que os recursos audiovisuais são utilizados em vários momentos do dia, para passar vídeos e músicas infantis.

Figura 2: área externa do berçário

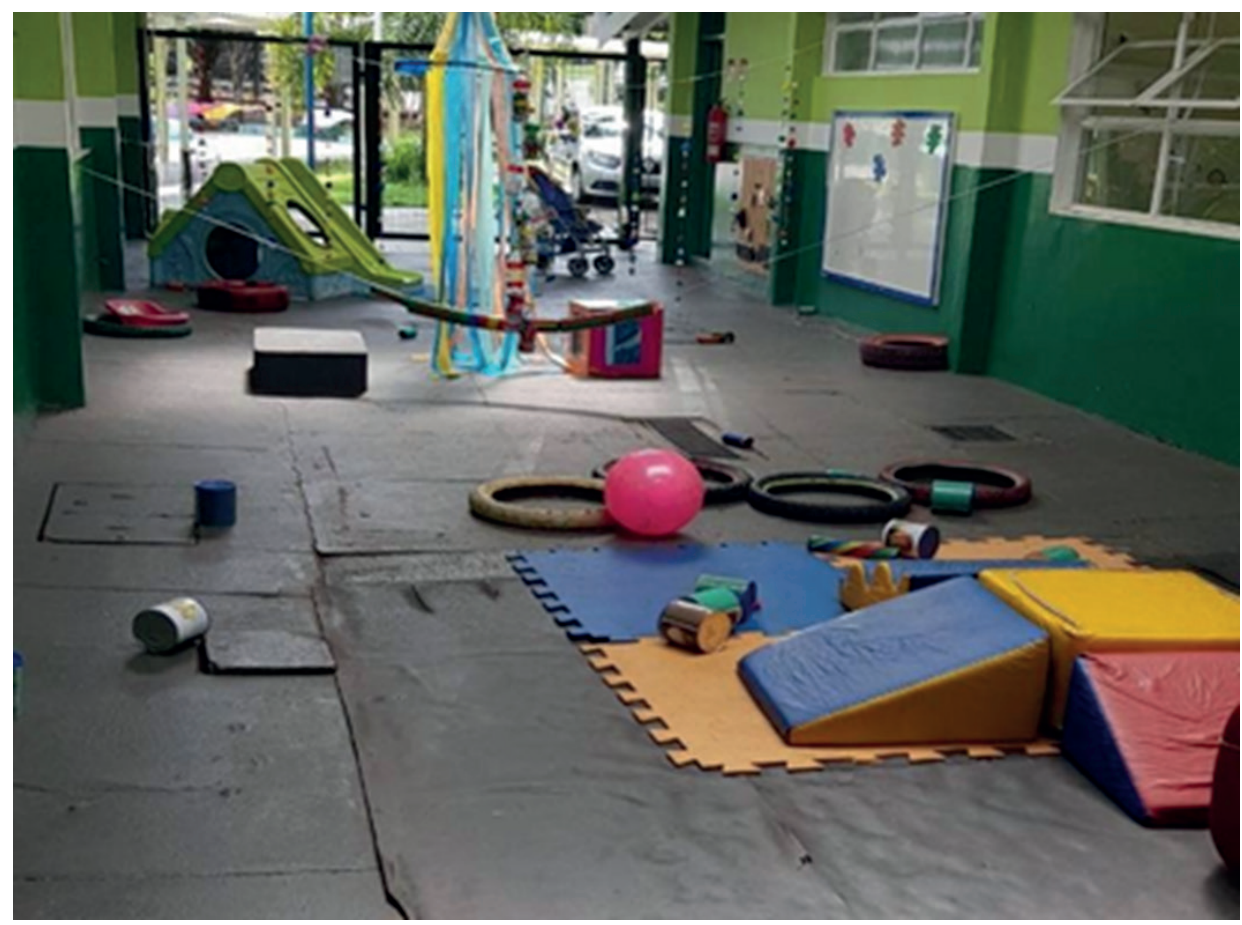

Fonte: acervo particular.

Notamos que os bebês constantemente interagem entre si, estabelecendo relações, realizando imitações, notando o que o outro está fazendo, emprestando brinquedos para outros, puxando brinquedos da mão de outra criança. Não há dificuldades para que interajam, porém, os conflitos são frequentes, com mordidas e puxões de cabelo, pois são pequenos e ainda estão aprendendo a manifestar-se através da linguagem. A liberdade que os bebês tem de andar pela sala permite que explorem o que há em sua volta, inclusive outros bebês.

No que diz respeito à relação entre professora e bebê, percebemos a afetividade constante. Quando pedem colo, não são negadas, não tem as suas necessidades afetivas tratadas com menor importância. Como consequência de sua liberdade de andar e buscar o que é de seu interesse, não é do costume das crianças chamar a professora para realizar seus 
desejos. Em vários momentos as professoras buscam trabalhar a autonomia dos bebês, estimulando-os a pegar e alcançar objetos. Notamos que há sempre um direcionamento das professoras para as ações dos bebês, mesmo que indireto.

Nos momentos de cuidados, todas as professoras são atenciosas, porém, nota-se que muitas atividades rotineiras são feitas mecanicamente, como se de modo automático. $\mathrm{O}$ banho, apesar de tentar deixar as crianças mais confortáveis - assim como o momento da alimentação - não é um momento de interação entre professora e bebê, e sim um atendimento às necessidades básicas da criança.

Ao entrelaçar os aspectos principais das teorias referenciadas e os observados na sala de Educação Infantil, levantamos alguns pontos que podem trazer contribuições acerca do cuidado e da educação de crianças pequenas. Dentro da perspectiva de Rousseau (1995), a criança deve ser livre para se movimentar e adquirir o controle de seu próprio corpo, o que vai ao encontro de práticas realizadas na turma observada, quando se oportuniza às crianças o livre brincar e o livre movimento, quando afirma:

O único que faz sua vontade é aquele que não precisa para tanto colocar o braço de outrem na ponta dos seus. Segue-se dai que o primeiro de todos os bens, não é a autoridade, mas a liberdade. $\mathrm{O}$ homem verdadeiramente livre só quer o que pode e fazo o que lhe agrada. Eis a minha máxima fundamental. Trata-se apenas de aplicá-la à infância, e todas as regras da educação decorrerão dela (ROUSSEAU, p. 76, 1995)

Na abordagem de Pikler (2004), as crianças devem ter ação autonoma e vimos que muitas atividades desenvolvidas proporcionam às crianças possibilidades diversas de desenvolverem a sua autonomia, nas interações com seus pares elas são provocadas a terem maior desenvoltura motora, cognitivo e criativa. Ressaltamos que a interferência do adulto impede à criança de fazer descobertas autônomas, quando isso acontece prevalece a decisão do adultos sobre o que se quer ela faça, em detrimento do que a criança deseja fazer, de acordo com a abordagem:

\footnotetext{
A intervenção do adulto, ensinando ou simplesmente interferindo nos movimentos e nos jogos do bebê, não apenas perturba a situação de independência, substituindo o interesse do bebê por seus próprios objetivos, como também aumenta artificialmente a dependência da criança, enquanto que a atitude de respeito à autonomia colocada, em lugar de um comportamento possessivo e autocrático dos pais, o fundamento de um sistema de relações pais-filhos em que ambos se consideram e confiam mutuamente. (FALK, 2004, p. 31)
}

Do mesmo modo, ao escalar um brinquedo, ao ir atrás de um objeto, ao descobrir algo novo, é importante que o faça por sua própria descoberta. À professora cabe organizar os tempos e espaços que proporcionem às crianças vivências que contribuam para o seu desenvolvimento. O momento da alimentação pode se tornar uma atividade autônoma, uma vez que a professora reconhece a desenvoltura da criança para segurar uma colher, sentar-se à 
mesa sozinha, "[...] para a criança estar sozinha não quer dizer estar abandonada, mais pode significar longos momentos de serenidade e de brincar tranquila" (FALK, p. 39, 2004).

Outro aspecto relevante dentro da perspectiva pikleriana é o valor dado a afetividade que é desenvolvida na relação entre professora e criança. Consideramos necessário ressaltar que são nos momentos de maior fragilidade e intimidade da criança que se estabelecem os vínculos afetivos. Portanto, atividades como o banho, trocas de fraldas, alimentação, e sono, devem proporcionar à criança pequena o maior conforto possível, por meio de diálogos, enunciando o que a professora está fazendo naquele momento, para que a criança conheça aquela pessoa que é responsável por ela.

O resgate dos referenciais estudados e as observações realizadas foram imprescindíveis para o dimensionamento de um trabalho de qualidade com crianças de zero a três anos. Destacamos, ainda que é de fundamental importância criar as circunstâncias para que professores em processo de formação possam ter acesso às abordagens teóricas estudadas, de maneira que reconheçam os aspectos a serem validados no processo educativo das crianças.

\section{O Que Valorizar na Prática Docente: Indicações Teórico- Práticas e Considerações Finais}

Consideramos relevante que se compreenda a necessidade de que professoras da primeira etapa da Educação Básica, especialmente as que atuam de zero a três anos, tenham conhecimentos teórico-práticos que subsidiem suas ações em salas de Educação Infantil, tendo a criança que está sob sua responsabilidade no centro do processo educativo.

Ressaltamos aqui aspectos relevantes já explicitados anteriormente, como a necessidade de libertar o corpo da criança em exercício de seu livre movimento, a fim de promover o movimento livre e o reconhecimento dos espaços em que circula. Destacamos a importância de se garantir o cuidado para com o atendimento das necessidades da criança, porém, sem torná-las em comando das crianças para que seus/suas professoras atendam suas vontades, assim como a necessidade de se pensar na educação para a vida, gradativa, desde a mais tenra idade (Rousseau, 2017).

Destacamos a importância de uma construção afetiva na relação entre professora e criança, pois o carinho e o cuidado são vistos como forma de colaborar para com o desenvolvimento integral das crianças. A professora responsável por uma turma de Educação Infantil, é igualmentente responsável por oportunizar às crianças situações em que explorem os ambientes de forma autônoma e criem as possibilidades de aprendizagens nas experiências vividas, assim a pessoa que cuida e educa as crianças deve estar em constante ação de observação para analisar e avaliar o desenvolvimento da crianças, sem interferir no processo de descoberta autônoma. (Falk, 2011)

O diálogo com os teóricos permite-nos perspectivar aspectos inprescindíveis à forma- 
ção profissional, especialmente as que se relacionam às crianças pequenas, seus cuidados e modos de descobrir o mundo e aprender. Bem como, o papel que os adultos exercem em suas vidas, e o que é importante à consolidação da prática docente.

A observação das crianças evidenciam temáticas necessárias a serem abordadas nos processos formativos de professoras em determinados contextos. Reiteramos a permanente necessidade de enfatizar que as profissionais tenham ciência do trabalho que fazem e que devem fazer com e pelas crianças, que estão sob sua responsabilidade, subsidiadas em diálogos teóricos e conhecimentos que Ihes permitam construir um aprendizado significativo que respeite as crianças em seus direitos.

A formação de professores não pode prescindir de conhecimentos sobre a especificidade das crianças e a valorização de seus conhecimentos. O reconhecimento de pressupostos teóricos para a construção de propostas educativas que valorizam as crianças como sujeitos dos seus processos educativos leva-nos a pensar em formação de professoras de Educação Infantil, que articule de forma crítica os fundamentos teórico-metodológicos historicamente construídos.

\section{Referências Bibliográficas}

FALK, Judit (Org.) Educar os Três Primeiros Anos: a experiência lóczy. 2ed. Araraquara, SP: Junqueira\&Marin, 2011.

ORTIZ, Cisele e CARVALHO, Teresa Venceslau de. Interações: ser professor de bebês - cuidar, educar e brincar, uma única ação. São Paulo, SP: Blucher, 2016. (Coleção InterAções).

ROUSSEAU, Jean Jacques. Emílio ou Da Educação. São Paulo, SP:Martins Fontes, 1995.

ROUSSEAU, Jean Jacques. Emílio ou Da Educação. São Paulo, SP:Edipro, 2017.

SOARES. Suzana, Macedo. Vínculo, movimento e autonomia. Educação até 3 anos. $1^{\text {a }}$ Ed. São Paulo: Ominisciência, 2017.

TARDOS, Anna. Autonomia e/ ou dependência. In: FALK. Judit (org) Abordagem Pikler. Educação Infantil. $1^{\text {a }}$ Ed. São Paulo: Omnisciência, 2016. 